\title{
Le Surréalisme et les arts du spectacle, éds. Sophie Bastien et Henri Béhar
}

\section{Nicola Ferrari}

\section{(2) OpenEdition}

1 Journals

\section{Edizione digitale}

URL: http://journals.openedition.org/studifrancesi/4455

DOI: $10.4000 /$ studifrancesi.4455

ISSN: 2421-5856

\section{Editore}

Rosenberg \& Sellier

\section{Edizione cartacea}

Data di pubblicazione: 1 settembre 2016

Paginazione: 360

ISSN: 0039-2944

\section{Notizia bibliografica digitale}

Nicola Ferrari, « Le Surréalisme et les arts du spectacle, éds. Sophie Bastien et Henri Béhar », Studi

Francesi [Online], 179 (LX | II) | 2016, online dal 01 septembre 2016, consultato il 18 septembre 2020.

URL : http://journals.openedition.org/studifrancesi/4455; DOI : https://doi.org/10.4000/studifrancesi. 4455

Questo documento è stato generato automaticamente il 18 settembre 2020.

\section{(c) (1)}

Studi Francesi è distribuita con Licenza Creative Commons Attribuzione - Non commerciale - Non opere derivate 4.0 Internazionale. 


\title{
Le Surréalisme et les arts du spectacle, éds. Sophie Bastien et Henri Béhar
}

\author{
Nicola Ferrari
}

\section{NOTIZIA}

Le Surréalisme et les arts du spectacle, dossier réuni et présenté par Sophie BASTIEN et Henri BÉHAR, Lausanne, L'Age d'Homme, 2014, «Mélusine» n. XXXIV, 319 pp.

1 Racconta Ionesco, con compiaciuta ironia, dello stupore di Breton, Soupault e Péret, all'accorgersi di quanto le loro intenzioni, intuizioni e convinzioni poetiche risultassero pienamente messe in scena proprio dal suo teatro. Come a dire, con paradosso tutto ioneschiano, che un (autentico) teatro surrealista nasceva solo fuori dal movimento surrealista, oltre e altrove rispetto ai suoi confini. L'aneddoto sembra offrire una risposta complessiva all'interrogazione del ricco dossier curato da Sophie Bastien e Henri Béhar in rapporto alle non lineari relazioni tra il Surrealismo e il teatro e, viceversa, agli aspetti del linguaggio scenico e drammaturgico novecentesco assimilabili a una più o meno marcata poetica surrealista. L'esperienza (e l'esigenza) di un teatro surrealista non si coglie entro il suo definito e delimitato alveo storico - come anello di congiunzione tra teatro simbolista e dell'assurdo, attraversando l'anarchica provocazione dadaista - quanto in prospettive decentrate (rispetto a figure autoriali, codici di genere o prospettive analitiche), demoralizzate nello spazio e liberamente fluenti nel tempo. In questo senso, persino l'esame dell'unica autentica concezione non-rappresentativa, onirica e destrutturata del linguaggio drammaturgico, effettivamente legata alla poetica di Breton, sembra prendere corpo e definizione nell'opera di Roger Vitrac solo passando attraverso le sue postume influenze su Beckett o Novarina (Michel coRvin, Les legs du surréalisme au théâtre, pp. 21-33) o alla sua capacità di ridefinire il significato della figura dello spettatore (Dina MANTCHEVA, Le rapport scènesalle dans le drame surréaliste, pp. 87-97) - così come la lezione di Artaud rivela la sua cifra surrealista solo nelle sue traduzioni performative in Jan Fabre o Matthew Barney 
(Jean-Yves SAMACHER, Antonin Artaud, précurseur de la performance contemporaine, pp. 203-214). Specularmente, la verifica di una dimensione teatrale nella poetica di Breton si vaglia al confronto con il pensiero secentesco di Rotrou e Pascal (Diana VLASIE, Le topos baroque du theatrum mundi, antidote au "peu de réalité", pp. 35-44), o nel suo possibile innesto extragenerico, nelle forme del récit e del romanzo (Misao HARADA, André Breton et la "règle des trois unités" comme rhétorique temporelle, pp. 73-85).

2 Seguendo il radicale (e straniante) nomadismo del sogno surrealista di teatro, il dossier esplora il processo di progressiva espansione spaziale - dalla scena rumena di Gellu Naum e Gherasim Luca al Théâtre Quotidien del Québec - e cronologica dall'inventario di eredità che sembrano invero moltiplicare i capitali surrealisti (e incarnarne finalmente $\mathrm{i}$ più segreti fantasmi) in Beckett (Henri BÉHAR, Le chaînon manquant, pp. 137-154) o Ionesco (Marie-Claude HUBERT, Ionesco, un héritier du surréalisme, pp. 155-166) alle scoperte risonanze surrealiste nel romanzo del secondo Novecento (Gabriel SAAD, Arts du spectacle et poétique du récit dans "La Marge" d'André Pieyre de Mandiargues, pp. 189-201), o ancora nei testi teatrali dell'estremo contemporaneo (Martine ANTLE, Réécriture du quotidien et du spectral dans le théâtre de Marie Ndaye, pp. 167-177). In questa prospettiva, la pubblicazione, all'interno del dossier, di Hanounan, pièce inedita di Georges RIBEMONT-DESSAIGNES (pp. 45-59), analizzata e decifrata da Gilles LOSSEROY (pp. 61-72), dimostra nel suo saporoso gioco d'avanguardia, la permeabilità e la reversibilità di tempi e poetiche, in un aurorale 1911, ancora in attesa della precisa definizione degli immaginari surrealisti e dadaisti a venire. 